\title{
Risk Factors and a New Prediction Model for Pancreatic Fistula After Pancreaticoduodenectomy
}

\author{
Jia-Yu Zhang (D) ${ }^{1,2}$ \\ Jia Huang (iD ${ }^{2}$ \\ Su-Ya Zhao ${ }^{3}$ \\ Xin Liu $^{4}$ \\ Zhen-Cheng Xiong ${ }^{5}$ \\ Zhi-Ying Yang (iD) ${ }^{1,2}$ \\ 'Graduate School of Peking Union \\ Medical College, Beijing, 100730, People's \\ Republic of China; ${ }^{2}$ Department of \\ General Surgery, China-Japan Friendship \\ Hospital, Beijing, 100029, People's \\ Republic of China; ${ }^{3}$ Beijing University of \\ Chinese Medicine, Beijing, I00029, \\ People's Republic of China; ${ }^{4}$ Graduate \\ School of Tianjin Medical University, \\ Tianjin, 30004I, People's Republic of \\ China; ${ }^{5}$ Institute of Medical Technology, \\ Peking University Health Science Center, \\ Beijing, 100029, People's Republic of \\ China
}

\begin{abstract}
Aim: In order to find the risk factors of postoperative pancreatic fistula (POPF) after pancreaticoduodenectomy (PD) according to the latest definition and grading system of International Study Group of Pancreatic Surgery (ISGPS) (version 2016) and propose a nomogram for predicting POPF.

Methods: We conducted a retrospective analysis of 232 successive cases of PD performed at our hospital by the same operator from August 2012 to June 2020. POPF was diagnosed in accordance with the latest definition of pancreatic fistula from the ISGPS. The risk factors of POPF were analyzed by univariate and multivariate logistic regression analysis. A nomogram model to predict the risk of POPF was constructed based on significant factors. Results: There were 18 cases of POPF, accounting for $7.8 \%$ of the total. Among them, 17 cases were classified into ISGPF grade B and 1 case was classified into ISGPF grade C. In addition, 35 cases were classified into biochemical leak. Univariate and multivariate analysis showed that hypertension, non-diabetes, no history of abdominal surgery, antecolic gastrojejunostomy and soft pancreas were independent risk factors of POPF. Based on significant factors, a nomogram is plotted to predict the risk of POPF. The $\mathrm{C}$-index of this nomogram to assess prediction accuracy was $0.916(\mathrm{P}<0.001)$ indicating good prediction performance.

Conclusion: Hypertension, non-diabetes, no history of abdominal surgery, antecolic gastrojejunostomy and soft pancreas were independent risk factors of POPF. Meanwhile, a nomogram for predicting POPF with good test performance and discriminatory capacity was constituted.
\end{abstract}

Keywords: pancreaticoduodenectomy, pancreatic fistula, International Study Group of Pancreatic Surgery, prediction model

\section{Introduction}

Pancreaticoduodenectomy (PD) is the primary treatment for malignant tumors involving the lower bile duct, the pancreatic head, and the duodenal ampulla., ${ }^{1,2}$ The surgical safety of PD has been greatly improved; nevertheless, PD remains one of the risky operations associated with relatively high morbidity and mortality rate. ${ }^{3}$ Postoperative pancreatic fistula (POPF) is still one of the most common complications after PD, and this complication also prolongs hospital stays and leads to high medical expenses. Meanwhile, POPF is associated with abdominal infection, delayed gastric emptying, and bleeding after PD. ${ }^{4-7}$ In order to minimize perioperative adverse outcomes and optimize clinical management, the risk factors of POPF need to be understood. In this work, we conducted a retrospective analysis of
Correspondence: Zhi-Ying Yang Department of General Surgery, ChinaJapan Friendship Hospital, 2 Cherry Blossom East Street, Beijing, 100029. People's Republic of China Email yangzhy@aliyun.com 
232 cases of PD performed by the same operator in the Department of Hepatobiliary Surgery of the China-Japan Friendship Hospital, China, to determine the risk factors for POPF and propose a nomogram for predicting POPF at the same time.

\section{Materials and Methods}

\section{Patients and Data Collection}

We reviewed the data from 232 successive cases of PD performed by the same operator in the Department of Hepatobiliary Surgery of the China-JapanFriendship Hospital, China, from August 2012 to June 2020. The following data were collected: age, gender, body mass index (BMI), hypertension, drinking history, pancreatitis history, diabetes mellitus (DM), complication, infectious diseases, history of abdominal surgery, preoperative biliary drainage, preoperative white blood cell count (WBC), preoperative neutrophil ratio, preoperative hemoglobin (HGB), preoperative platelet (PLT), preoperative total bilirubin, preoperative serum albumin, preoperative serum creatinine (Scr), pylorus preserving, operative time, blood loss, intraoperative red blood cell transfusion, intraoperative plasma transfusion, drainage of pancreatic duct stent, pancreatic texture, position of the gastrojejunostomy, jejunostomy and combined vascular resection. Among them, the data of hypertension, drinking history, the history of abdominal surgery and so on all come from the consultation records and physical examination records in the medical records. Pancreatic texture (soft vs hard) was defined subjectively, as judged intraoperatively by the surgeon. Additionally, all postoperative complications were recorded. All 232 cases were included in this study.

\section{Preoperative Preparation}

Prior to surgery, all patients underwent routine examinations, tests and evaluations of organ function. We consider that patients with obstructive jaundice who have a poor mental state, severe dehydration, poor nutrition, or severe jaundice should receive preoperative biliary drainage and supportive therapy to improve their nutritional condition. Patients should undergo surgery after their general condition has improved.

\section{Surgical Approach}

Surgical technique was largely performed by standard procedures. Generally, the operation was performed by using either classic PD or pylorus-preserving PD (PPPD) techniques. End-to-side, mucosa-mucosa anastomosis was the first choice for pancreaticojejunostomy. In cases of very narrow pancreatic duct, or if it was impossible to expose the pancreas, an end-to-end pancreaticojejunostomy was performed. Usually, 3 abdominal drainage tubes were applied. One drainage tube was placed near the site of bile duct anastomosis, and the other 2 tubes were placed near the site of the pancreatic anastomosis and splenic fossa.

\section{Classification and Definition of Postoperative Pancreatic Fistula}

According to the 2016 update of the International Study Group for Pancreatic Fistula (ISGPF) definition and grading of postoperative pancreatic fistula (POPF), a POPF is now redefined as a drain output of any measurable volume of fluid with an amylase level $>3$ times the upper limit of institutional normal serum amylase activity, associated with a clinically relevant development related directly to the POPF. The former "grade A POPF" is now redefined and called a "biochemical leak," because it has no clinical importance and is no longer referred to a true PF. POPF grades B and C are confirmed but defined more strictly. In particular, grade $B$ requires a change in the postoperative management; drains are either left in place $>3$ weeks or repositioned through endoscopic or percutaneous procedures. Grade $\mathrm{C}$ POPF refers to those POPF that require reoperation or lead to single or multiple organ failure and/or mortality attributable to the PF.

\section{Statistical Analysis}

Clinical data were entered into an Excel spreadsheet, and SPSS 25.0 software (IBM, Armonk, New York, USA) was used for statistical analyses. Measurement data are expressed as the mean $\pm \mathrm{SD}$. Kolmogorov-Smirnov tests were applied to test for the normality of continuous variables. An independent sample $t$-test was performed for between-group comparisons. Categorical variables were analyzed using $x^{2}$ test and the Fisher's exact test. Variables were incorporated into a univariate analysis. $P<0.05$ was considered statistically significant. Factors with $\mathrm{P}<0.5$ in the univariate analysis were incorporated into a multivariate logistic regression analysis to identify the independent factors for the POPF. The strength of the association was evaluated with odds ratios (ORs) and 95\% confidence intervals (CIs). Nomogram was 
plotted for significant factors using regression modelling strategies (rms) program in the R software version 3.5.0.

\section{Results \\ Overall Characteristics of Patients and Operative Times}

This study included 148 male patients and 84 female patients with a mean age of $62.18 \pm 11.37$ years. The mean hospital stay was $31.14 \pm 14.62 \mathrm{~d}$. The mean operative time was $300.72 \pm 76.10 \mathrm{~min}$. The condition (confirmed by pathology) of the 232 patients is shown in Table 1. Among the 232 patients, $128(55.2 \%)$ underwent complications, and 18 (7.8\%) had POPF, including 17 (7.3\%) cases of grade B PF and $1(0.4 \%)$ case of grade C. Additionally, the following complications were identified: 35 (15.1\%) cases of biochemical leak, $36(15.5 \%)$ cases of postoperative haemorrhage, 5 $(2.2 \%)$ cases of bile leakage, $83(35.8 \%)$ cases of delayed gastric emptying, 30 (12.9\%) cases of abdominal infection, 7 $(3.0 \%)$ cases of pulmonary infection, $5(2.2 \%)$ cases of heart failure and $4(1.7 \%)$ cases of respiratory failure. Moreover, 38 (16.4\%) patients underwent unplanned readmission (within 30 days) due to the above complications. It is worth mentioning that there were no perioperative deaths.

Table I Disease Composition

\begin{tabular}{|l|c|}
\hline Pathological Type & N \\
\hline Bile duct cancer & $46(19.83 \%)$ \\
Gallbladder cancer & $5(2.16 \%)$ \\
Choledochal cyst & $1(0.43 \%)$ \\
Retroperitoneal neoplasm (Lymphoma) & $1(0.43 \%)$ \\
Retroperitoneal neoplasm (Sarcoma) & $1(0.43 \%)$ \\
Periampullary cancer & $59(25.43 \%)$ \\
Chronic pancreatitis & $7(3.02 \%)$ \\
Duodenal cancer & $15(6.47 \%)$ \\
Duodenal stromal tumor & $4(1.72 \%)$ \\
Benign duodenal tumor & $2(0.86 \%)$ \\
Duodenal neuroendocrine tumor & $1(0.43 \%)$ \\
Gastric cancer & $2(0.86 \%)$ \\
Pancreatic ductal adenocarcinoma & $70(30.17 \%)$ \\
Pancreatic serous cystadenoma & $2(0.86 \%)$ \\
Pancreatic neuroendocrine tumor (GI) & $1(0.43 \%)$ \\
Pancreatic neuroendocrine tumor (G2) & $6(2.59 \%)$ \\
Pancreatic neuroendocrine tumor (G3) & $2(0.86 \%)$ \\
Pancreatic schwannoma & $1(0.43 \%)$ \\
Metastatic cancer & $2(0.86 \%)$ \\
IgG4-related disease & $2(0.86 \%)$ \\
Intraductal papillary mucinous neoplasm & $2(0.86 \%)$ \\
Total & 232 \\
\hline
\end{tabular}

\section{Univariate Analysis}

Univariate analysis disclosed no significant correlation between POPF and the following factors: gender, age, body mass index (BMI), drinking history, pancreatitis history, diabetes mellitus, complication, infectious diseases, history of abdominal surgery, preoperative biliary drainage, preoperative $\mathrm{WBC}$, preoperative neutrophil ratio, preoperative HGB, preoperative PLT, preoperative total bilirubin, preoperative serum albumin, preoperative Scr, pylorus preserving, operative time, blood loss, intraoperative red blood cell transfusion, intraoperative plasma transfusion, drainage of pancreatic duct stent, position of the gastrojejunostomy, jejunostomy and combined vascular resection. Conversely, a significant correlation was showed between POPF and the following factors: Hypertension (yes vs no: $12.5 \%$ vs $5.3 \%, P=0.050$ ) and pancreatic texture (soft vs hard: $31.1 \%$ vs $2.1 \%, P<0.001$ ) (Table 2 ).

\section{Multivariate Logistic Regression Analysis}

The potential risk factors for POPF (age, BMI, hypertension, drinking history, diabetes mellitus, history of abdominal surgery, preoperative neutrophil ratio, preoperative HGB, preoperative Scr, operative time, pancreatic texture, position of the gastrojejunostomy) screened out in the univariate analysis were incorporated into the logistic regression analysis. The results showed that hypertension, non-diabetes, no history of abdominal surgery, antecolic gastrojejunostomy and soft pancreas were independent predictive factors of POPF (Table 3).

\section{Prediction Model}

A nomogram model to predict the risk of POPF was constructed based on significant factors, as displayed in Figure 1. Factors in nomogram model included hypertension, diabetes, history of abdominal surgery, position of the gastrojejunostomy and pancreatic texture. For example, assuming a patient with hypertension (33 points), non-diabetes (89 points), no history of abdominal surgery (61 points), retrocolic gastrojejunostomy (0 point) and soft pancreas (100 points), the probability of POPF was estimated to be $56 \%$.

\section{Discussion}

Pancreatic fistula after pancreaticoduodenectomy is a common and serious complication and the most significant cause of subsequent complications and death. ${ }^{8-11}$ The early identification of patients with a higher risk of POPF is critical to improving perioperative management. So far, researchers believe that the following factors are related to POPF: gender, 
Table 2 Risk Factors for Postoperative Pancreatic Fistula According to Univariate Analysis

\begin{tabular}{|c|c|c|c|c|}
\hline \multirow[t]{2}{*}{ Variable } & \multicolumn{4}{|c|}{ Pancreatic Fistula } \\
\hline & $\begin{array}{c}\text { No } \\
(n=2 \mid 4)\end{array}$ & $\begin{array}{c}\text { Yes } \\
(n=18)\end{array}$ & $x^{2}$ & $P$ value \\
\hline $\begin{array}{l}\text { Sex } \\
\qquad \text { Male } \\
\text { Female }\end{array}$ & $\begin{array}{c}136(63.55 \%) \\
78(36.45 \%)\end{array}$ & $\begin{array}{c}12(66.67 \%) \\
6(33.33 \%)\end{array}$ & 0.070 & 0.792 \\
\hline $\begin{array}{l}\text { Age }(y r) \\
\quad \geq 65 \\
\quad<65\end{array}$ & $\begin{array}{c}93(43.46 \%) \\
12 \mid(56.54 \%)\end{array}$ & $\begin{array}{c}10(55.56 \%) \\
8(44.44 \%)\end{array}$ & 0.984 & 0.321 \\
\hline BMI $\left(\mathrm{kg} / \mathrm{m}^{2}\right)$ & $23.09 \pm 3.30$ & $24.16 \pm 2.75$ & & 0.182 \\
\hline $\begin{array}{l}\text { Hypertension } \\
\text { Yes } \\
\text { No }\end{array}$ & $\begin{array}{l}70(32.71 \%) \\
144(67.29 \%)\end{array}$ & $\begin{array}{l}10(55.56 \%) \\
8(44.44 \%)\end{array}$ & 3.836 & 0.050 \\
\hline $\begin{array}{l}\text { Drinking history } \\
\text { Yes } \\
\text { No }\end{array}$ & $\begin{array}{l}60(28.04 \%) \\
154(71.96 \%)\end{array}$ & $\begin{array}{c}7(38.89 \%) \\
1 \mathrm{I}(61.11 \%)\end{array}$ & 0.952 & 0.329 \\
\hline $\begin{array}{l}\text { Pancreatitis history } \\
\text { Yes } \\
\text { No }\end{array}$ & $\begin{array}{c}10(4.67 \%) \\
204(95.33 \%)\end{array}$ & $\begin{array}{c}0(0.00 \%) \\
18(100.00 \%)\end{array}$ & 0.111 & 0.739 \\
\hline $\begin{array}{l}\text { Diabetes mellitus } \\
\text { Yes } \\
\text { No }\end{array}$ & $\begin{array}{c}43(20.09 \%) \\
|7|(79.9 \mid \%)\end{array}$ & $\begin{array}{c}\text { I(5.56\%) } \\
\text { I7(94.44\%) }\end{array}$ & 1.435 & 0.209 \\
\hline $\begin{array}{l}\text { Complication } \\
\text { Yes } \\
\text { No }\end{array}$ & $\begin{array}{l}139(64.95 \%) \\
75(35.05 \%)\end{array}$ & $\begin{array}{c}12(66.67 \%) \\
6(33.33 \%)\end{array}$ & 0.021 & 0.884 \\
\hline $\begin{array}{l}\text { Infectious disease } \\
\text { Yes } \\
\text { No }\end{array}$ & $\begin{array}{c}17(7.94 \%) \\
197(92.06 \%)\end{array}$ & $\begin{array}{c}2(11.11 \%) \\
16(88.89 \%)\end{array}$ & 0.001 & 0.648 \\
\hline $\begin{array}{l}\text { History of abdominal surgery } \\
\text { Yes } \\
\text { No }\end{array}$ & $\begin{array}{c}45(21.03 \%) \\
169(78.97 \%)\end{array}$ & $\begin{array}{c}\text { I(5.56\%) } \\
\text { I7(94.44\%) }\end{array}$ & 1.622 & 0.135 \\
\hline $\begin{array}{l}\text { Preoperative biliary drainage } \\
\text { Yes } \\
\text { No }\end{array}$ & $\begin{array}{c}80(37.38 \%) \\
134(62.62 \%)\end{array}$ & $\begin{array}{c}8(44.44 \%) \\
10(55.56 \%)\end{array}$ & 0.352 & 0.553 \\
\hline $\begin{array}{l}\text { WBC(/L) } \\
\leq 10 * 10^{9} \\
>10 * 10^{9}\end{array}$ & $\begin{array}{c}191(89.25 \%) \\
23(10.75 \%)\end{array}$ & $\begin{array}{c}15(83.33 \%) \\
3(16.67 \%)\end{array}$ & 0.141 & 0.435 \\
\hline $\begin{array}{l}\text { Neutrophil ratio } \\
\quad \leq 70 \% \\
>70 \%\end{array}$ & $\begin{array}{c}135(63.08 \%) \\
79(36.92 \%)\end{array}$ & $\begin{array}{c}13(72.22 \%) \\
5(27.78 \%)\end{array}$ & 0.600 & 0.438 \\
\hline $\begin{array}{l}\mathrm{HGB}(\mathrm{g} / \mathrm{L}) \\
\quad \geq 120 \\
\quad<120\end{array}$ & $\begin{array}{l}\text { II } 2(52.34 \%) \\
102(47.66 \%)\end{array}$ & $\begin{array}{l}\text { II (6I.II\%) } \\
7(38.89 \%)\end{array}$ & 0.513 & 0.474 \\
\hline
\end{tabular}

(Continued) 
Table 2 (Continued).

\begin{tabular}{|c|c|c|c|c|}
\hline \multirow[t]{2}{*}{ Variable } & \multicolumn{4}{|c|}{ Pancreatic Fistula } \\
\hline & $\begin{array}{c}\text { No } \\
(n=2 \mid 4)\end{array}$ & $\begin{array}{c}\text { Yes } \\
(n=18)\end{array}$ & $x^{2}$ & $P$ value \\
\hline $\begin{array}{l}\mathrm{PLT}(/ \mathrm{L}) \\
\quad \geq 100 * 10^{9} \\
\quad<100 * 10^{9}\end{array}$ & $\begin{array}{c}211(98.60 \%) \\
3(1.40 \%)\end{array}$ & $\begin{array}{c}\text { I7(94.44\%) } \\
\text { I()5.56\% }\end{array}$ & 0.128 & 0.278 \\
\hline $\begin{array}{l}\text { Preoperative total bilirubin }(\mu \mathrm{mol} / \mathrm{L}) \\
\quad \leq 17 \mathrm{I} \\
>17 \mathrm{I}\end{array}$ & $\begin{array}{l}\text { I54(7I.96\%) } \\
60(28.04 \%)\end{array}$ & $\begin{array}{c}14(77.78 \%) \\
4(22.22 \%)\end{array}$ & 0.065 & 0.785 \\
\hline $\begin{array}{l}\text { Serum albumin }(g / L) \\
\quad \geq 35 \\
\quad<35\end{array}$ & $\begin{array}{c}169(78.97 \%) \\
45(21.03 \%)\end{array}$ & $\begin{array}{c}13(72.22 \%) \\
5(27.78 \%)\end{array}$ & 0.137 & 0.551 \\
\hline $\operatorname{Scr}(\mu \mathrm{mol} / \mathrm{L})$ & $66.65 \pm 24.64$ & $71.53 \pm 12.88$ & & 0.407 \\
\hline $\begin{array}{l}\text { Pylorus-preserving } \\
\text { Yes } \\
\text { No }\end{array}$ & $\begin{array}{l}28(\mid 3.08 \%) \\
186(86.92 \%)\end{array}$ & $\begin{array}{l}2(11.11 \%) \\
16(88.89 \%)\end{array}$ & $<0.001$ & 1.000 \\
\hline $\begin{array}{l}\text { Operative time }(\mathrm{min}) \\
\quad \leq 300 \\
>300\end{array}$ & $\begin{array}{l}\text { II5(53.74\%) } \\
99(46.26 \%)\end{array}$ & $\begin{array}{l}8(44.44 \%) \\
10(55.56 \%)\end{array}$ & 0.576 & 0.448 \\
\hline $\begin{array}{l}\text { Blood loss }(\mathrm{mL}) \\
\quad>500 \\
\leq 500\end{array}$ & $\begin{array}{l}\text { I I } 2(52.34 \%) \\
\text { I02(47.66\%) }\end{array}$ & $\begin{array}{l}10(55.56 \%) \\
8(44.44 \%)\end{array}$ & 0.069 & 0.793 \\
\hline $\begin{array}{l}\text { Intraoperative red blood cell } \\
\text { transfusion } \\
\text { No } \\
\text { Yes }\end{array}$ & $\begin{array}{l}\text { III(5I.87\%) } \\
\text { I03(48.13\%) }\end{array}$ & $\begin{array}{l}9(50.00 \%) \\
9(50.00 \%)\end{array}$ & 0.023 & 0.879 \\
\hline $\begin{array}{l}\text { Intraoperative plasma transfusion } \\
\text { No } \\
\text { Yes }\end{array}$ & $\begin{array}{l}126(58.88 \%) \\
88(41.12 \%)\end{array}$ & $\begin{array}{l}10(55.56 \%) \\
8(44.44 \%)\end{array}$ & 0.076 & 0.783 \\
\hline $\begin{array}{l}\text { Drainage of pancreatic duct stent } \\
\text { Yes } \\
\text { No }\end{array}$ & $\begin{array}{c}178(83.18 \%) \\
36(16.82 \%)\end{array}$ & $\begin{array}{c}15(83.33 \%) \\
3(16.67 \%)\end{array}$ & $<0.001$ & 1.000 \\
\hline $\begin{array}{l}\text { Pancreatic texture } \\
\text { Soft } \\
\text { Hard }\end{array}$ & $\begin{array}{c}31(14.49 \%) \\
183(85.51 \%)\end{array}$ & $\begin{array}{c}14(77.78 \%) \\
4(22.22 \%)\end{array}$ & 38.590 & $<0.001$ \\
\hline $\begin{array}{l}\text { Gastrojejunostomy } \\
\text { Retrocolic } \\
\text { Antecolic }\end{array}$ & $\begin{array}{l}180(84.11 \%) \\
34(\mid 5.89 \%)\end{array}$ & $\begin{array}{c}12(66.67 \%) \\
6(33.33 \%)\end{array}$ & 2.424 & 0.096 \\
\hline $\begin{array}{l}\text { Jejunostomy } \\
\text { Yes } \\
\text { No }\end{array}$ & $\begin{array}{c}204(95.33 \%) \\
10(4.67 \%)\end{array}$ & $\begin{array}{c}18(100.00 \%) \\
0(0.00 \%)\end{array}$ & 0.111 & 0.739 \\
\hline $\begin{array}{l}\text { Vascular resection } \\
\text { Yes } \\
\text { No }\end{array}$ & $\begin{array}{c}25(\mid 1.68 \%) \\
\mid 89(88.32 \%)\end{array}$ & $\begin{array}{c}0(0.00 \%) \\
18(100.00 \%)\end{array}$ & 1.298 & 0.231 \\
\hline
\end{tabular}


Table 3 Logistic Regression for the Predictors of Postoperative Pancreatic Fistula After Pancreaticoduodenectomy

\begin{tabular}{|l|c|c|c|c|c|}
\hline Variable & B & SE & P value & OR & 95\% CI \\
\hline Hypertension & 1.250 & 0.637 & 0.050 & 3.492 & $1.002-12.168$ \\
Non-diabetes & 3.409 & 1.405 & 0.015 & 30.235 & $1.924-475.097$ \\
No history of abdominal surgery & 2.326 & 1.153 & 0.044 & 10.237 & $1.068-98.071$ \\
Soft pancreas & 3.805 & 0.780 & $<0.001$ & 44.931 & $9.745-207.161$ \\
Antecolic gastrojejunostomy & 2.156 & 0.813 & 0.008 & 8.632 & $1.754-42.486$ \\
\hline
\end{tabular}

age, preoperative jaundice, BMI, operative time, intraoperative blood loss, pancreatic texture, diameter of the main pancreatic duct, and early postoperative C-reactive protein values. ${ }^{12-18}$ The data related to the diameter of the pancreatic canal and C-reactive protein values were insufficient in our medical records; therefore, this study cannot draw any conclusion about these factors. Nevertheless, our data showed that the gender, age, BMI, preoperative jaundice, intraoperative blood loss, and operative time had no relevance in the prediction of POPF. Besides, in this study, multivariate logistic regression analysis showed that hypertension, non-diabetes, no history of abdominal surgery, antecolic gastrojejunostomy and soft pancreas were independent risk factors for pancreatic fistula after pancreaticoduodenectomy.

Soft pancreatic parenchyma is the most widely recognized risk factor for pancreatic fistula. ${ }^{19-21}$ Despite the subjectivity of the manual perception of the pancreatic stiffness may limit the reproducibility of the score, the surgeon evaluation remains the gold standard for pancreatic texture assessment. $^{22}$ In this study, 45 patients had a soft pancreas (POPF rate: $31.11 \%$ ), and 187 patients had a hard pancreas
(POPF rate: $2.14 \%$ ). Univariate analysis revealed that the difference was significant $(\mathrm{P}<0.001)$, suggesting that patients with a soft pancreas were at a higher risk of developing into a POPF after PD than patients with a hard pancreas. Additionally, multivariate logistic regression analysis showed that the difference was significant $(\mathrm{P}<0.001)$, which told that a soft pancreas was an independent risk factor for POPF after PD. The OR (44.931, 95\% CI: 9.745-207.161) showed that the risk of causing a pancreatic fistula after PD was 44.931-fold higher in patients with a soft pancreas than a hard pancreas. We provide several possible explanations for the relation between the risk of fistula development and a soft pancreatic texture. First, a soft pancreas is easily injured either directly or by ischemia caused by stitches placed between the pancreas parenchyma and the seromuscular layer of the jejunum. ${ }^{23}$ Second, in soft pancreases there is no pancreatic duct dilatation, which makes secure duct-tomucosa anastomosis difficult. ${ }^{19,24}$ Finally, and probably most significant, a soft pancreas has better exocrine function, and thus secretes more pancreatic juices, which are rich in proteolytic enzymes. $^{24,25}$

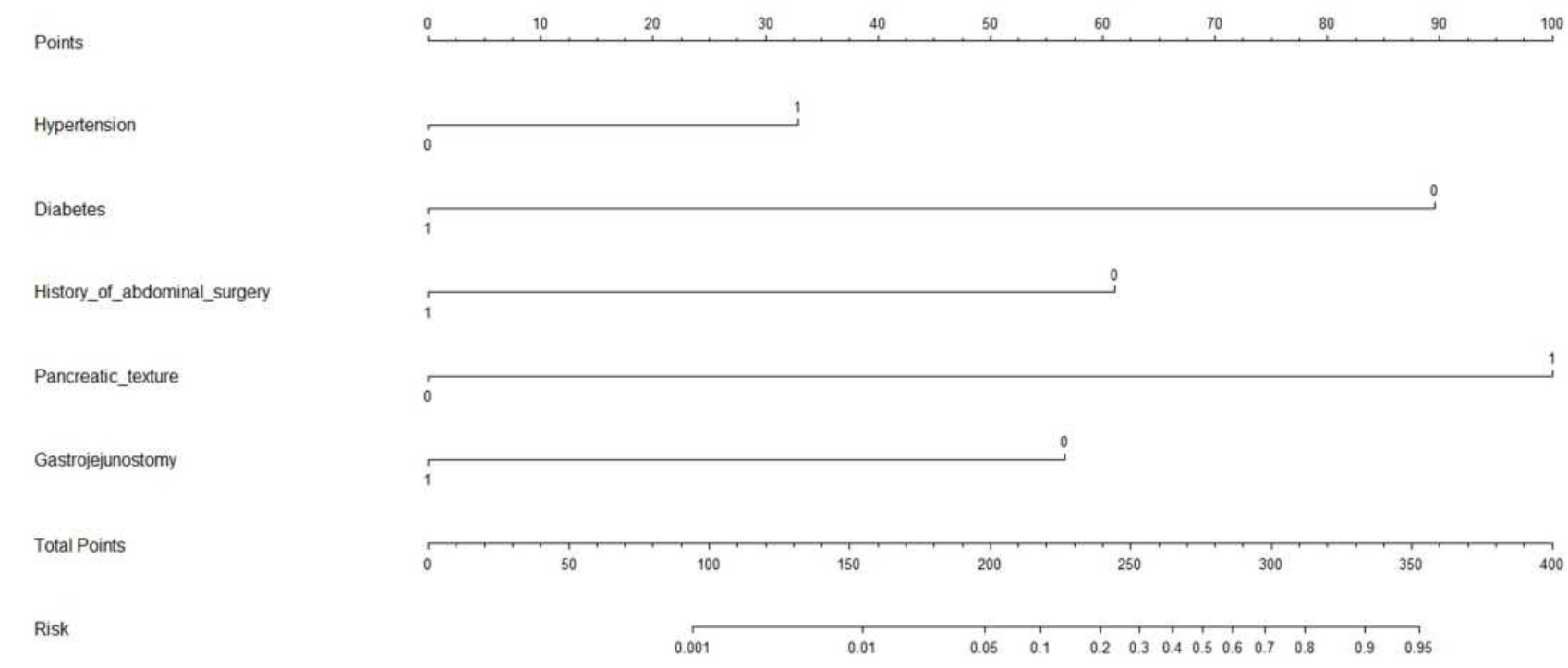

Figure I Nomogram calculator in prediction for postoperative pancreatic fistula after pancreaticoduodenectomy. 
$\mathrm{Hu}$ et $\mathrm{al}^{26}$ retrospectively analyzed 539 cases of $\mathrm{PD}$ and summed up that a nondiabetic was risk factor for pancreatic fistula in univariate analysis, although not in multivariate analysis. A meta-analysis ${ }^{21}$ including 16 clinical studies found that DM was associated with a decreased risk of POPF. However, patients without DM were at a higher risk of developing POPF. Some studies have been made to investigate the association between the presence of DM and POPF. Addeo et $\mathrm{al}^{27}$ found that the absence of preoperative diabetes was an independent risk factor for POPF. Lin et $\mathrm{al}^{19}$ reported that patients without DM were at a higher risk for POPF compared with patients with diabetes $(12.0 \%$ vs $7.7 \%)$. This study included 44 preoperative diabetic patients (POPF rate: $2.27 \%$ ) and 188 preoperative non-diabetic patients (POPF rate: $9.04 \%$ ). Multivariate logistic regression analysis revealed that the difference was significant $(P=0.015)$, which showed that a diabetes was a protective factor for POPF after PD. The OR (30.235, 95\% CI: 1.924-475.097) told that the risk of forming a pancreatic fistula after PD was 30.235-fold higher in preoperative non-diabetic patients than preoperative diabetic patients. A possible interpretation for this finding was revealed by Mathur et al. They claimed that patients with DM may have less fat and more pancreatic fibrosis, ${ }^{20,28,29}$ protecting them from developing POPF. We have similar views on this aspect that the decreased incidence of POPF in patients with diabetes was likely to be related to the decreased frequency of high risk features of the pancreas.

Some studies have reported that hypertension is associated with several complications after operations. ${ }^{30,31}$ Weber et $\mathrm{al}^{32}$ found that preoperative hypertension was negatively associated with survival after PD. In this work, 80 patients had preoperative hypertension (POPF rate: $12.50 \%$ ) and 152 patients did not (POPF rate: 5.26\%). Univariate analysis told that the difference in the POPF rates was significant $(P=0.05)$, indicating that patients with preoperative hypertension were at a higher risk of forming a POPF after PD than patients without preoperative hypertension. In addition, multivariate logistic regression analysis manifested that the difference was significant $(\mathrm{P}=0.05)$, which indicated that a preoperative hypertension was an independent risk factor for POPF after PD. The OR (3.492, 95\% CI: 1.002-12.168) manifested that the risk of developing a pancreatic fistula after PD was 3.492-fold higher in patients with a preoperative hypertension than in patients without a preoperative hypertension. The reasons why hypertension would be associated with pancreatic fistula are not as obvious. Perhaps some of the various medications typically prescribed to such patients (aspirin, angiotensin converting enzyme inhibitors, $\beta$ blockers, etc.) compromise anastomotic healing. ${ }^{19}$

Zhou et $\mathrm{al}^{33}$ reported that there was no significant correlation between the abdominal surgery history and POPF. Hanna et $\mathrm{al}^{34}$ found that antecolic gastrojejunostomy seems to be associated with less delayed gastric emptying, with no association with pancreatic fistula. Sahora et $\mathrm{al}^{35}$ retrospectively compared 400 patients with antecolic gastrojejunostomy with 400 patients with retrocolic gastrojejunostomy and summarized that the rate of POPF was higher in the retrocolic group $(11 \%$ vs $6 \% ; \mathrm{P}=$ $0.011)$. In this study, 46 patients had a history of abdominal surgery (POPF rate: $2.17 \%$ ) and 186 patients did not (POPF rate: 9.14\%). Multivariate logistic regression analysis manifested that the difference was significant $(\mathrm{P}=$ 0.044), which showed that a history of abdominal surgery was a protective factor for POPF after PD. The OR (10.237, 95\% CI: 1.068-98.071) manifested that the risk of developing a POPF after PD was 10.237-fold higher in patients without a a history of abdominal surgery than in patients with a history of abdominal surgery. At the same time, our study showed that antecolic gastrojejunostomy was performed in 40 patients (POPF rate: $15.00 \%$ ), and retrocolic gastrojejunostomy was performed in 192 patients (POPF rate: 6.25\%). Multivariate logistic regression analysis manifested that the difference was significant $(\mathrm{P}=0.008)$, indicating that antecolic gastrojejunostomy was an independent risk factor for pancreatic fistula after PD. The OR (8.632, 95\% CI: 1.754-42.486) manifested that the risk of causing a pancreatic fistula after PD was 8.632-fold higher in patients who experienced antecolic gastrojejunostomy than in patients who underwent retrocolic gastrojejunostomy. Finally, the full impact of abdominal surgery history and the position of the gastrojejunostomy on POPF is not well understood. However, it is our belief that previous surgery resulted in adhesion of tissues in the abdominal cavity. Compared with patients with no history of surgery, patients who have undergone abdominal surgery have a more fixed position of organs in the abdominal cavity. Therefore, the range of motion of the pancreatic anastomosis after PD is smaller, which reduces the risk of POPF. Similarly, the pancreatic anastomosis of patients who have undergone a retrocolic gastrojejunostomy is fixed to the transverse mesocolon with a smaller range of motion, thereby reducing the incidence of POPF. However, considering that antecolic gastrojejunostomy may be an effective way to reduce the incidence of delayed gastric emptying, we 
believe that more discussion and research on the optimal choice of gastrojejunostomy is needed in the future.

We believe that the exact causal mechanism of any observed connections in this study are secondary considerations and do not detract from the predictive capacity of the nomogram. It should be observed that all included variables had independent effects in adjusted models without significant statistical interaction, indicating additive risks at the patient level regardless of the underlying mechanism.

Previous studies analyzed risk factors for POPF and developed risk prediction tool using scoring system. ${ }^{22,36-40}$ However, few studies have built a nomogram based on individual risk factors. After our extensive review, only one study has tried to develop a nomogram for the prediction of POPF. ${ }^{41}$ In contrast, we use completely different risk factors to make the nomogram, and our nomogram has a higher upper limit of the prediction rate $(0.95>0.7)$. To the best of our knowledge, this study is also the first report demonstrating that antecolic gastrojejunostomy and no history of abdominal surgery can predict the development of pancreatic fistula. Ideally, fistula risk assessment begins in the preoperative process. However, there are limitations of such an approach. Nowadays, although preoperative risk stratification systems are becoming more prevalent, they rarely actually disqualify patients from undergoing potentially curative resection for premalignant, malignant, and symptomatic periampullary conditions. ${ }^{42-44}$ In addition, the majority of patients who are offered an operation can expect to have some prolongation of survival, irrespective of the burden of comorbid conditions. ${ }^{45}$ What is more, preoperative risk factors can not fully and accurately evaluate the development of postoperative pancreatic fistula. Therefore, the identification of these preoperative and intraoperative risk factors and the application of the nomogram can help tailor the postoperative management for patients who are at an increased risk of developing pancreatic fistula, including drain management, and the administration of antibiotics, a protease inhibitor, octreotide, or enteral nutrition. ${ }^{46}$

\section{Limitation}

Our analysis has limitations. First, this work is a retrospective analysis; therefore, the possibility of bias cannot be eliminated. Second, the number of patients in each group may have underpowered our statistical evaluation. Third, it is hard to generalize our conclusions given the study was performed at a single-institution. Finally, though we assessed a number of variables, the effects of unmeasured confounders cannot be ignored. To overcome these limitations, a prospective multicenter study with more patients is necessary.

\section{Conclusion}

Hypertension, non-diabetes, no history of abdominal surgery, antecolic gastrojejunostomy and soft pancreas were independent risk factors of POPF. Accordingly, we developed a nomogram which accurately predicts, with excellent discrimination, the development of postoperative pancreatic fistula after pancreatoduodenectomy. This nomogram can be readily learned, and can help surgeons anticipate, identify, and control pancreatic fistula proactively, with the aim of achieving better outcomes from this daunting postoperative complication. However, external validation of these new risk factors of POPF and of this nomogram is needed in further prospective studies.

\section{Ethical Approval}

The Ethics Committee of China-Japan Friendship Hospital consented to review the anonymous clinical data retrospectively and approved the study (2017-RC-2). A retrospective study does not require informed consent, which has been approved by the ethics committee. This study was conducted in accordance with the Declaration of Helsinki. All patient data was guaranteed to be confidential, and the researchers were committed to protecting the privacy and personal identity information of patients.

\section{Funding}

This study was financially supported by the Fund of China-Japan Friendship Hospital (No. 2017-RC-2).

\section{Disclosure}

The authors report no conflicts of interest for this work.

\section{References}

1. Brown EG, Yang A, Canter RJ, Bold RJ. Outcomes of pancreaticoduodenectomy: where should we focus our efforts on improving outcomes? JAMA Surg. 2014;149:694. doi:10.1001/jamasurg.2014.151]

2. Yamashita Y, Shirabe K, Tsujita E, et al. Surgical outcomes of pancreaticoduodenectomy for periampullary tumors in elderly patients. Langenbecks Arch Surg. 2013;398:539-545. doi:10.1007/s00423013-1061-x]

3. Sato N, Yabuki K, Kohi S, et al. Stapled gastro/duodenojejunostomy shortens reconstruction time during pylorus-preserving pancreaticoduodenectomy. World J Gastroenterol. 2013;19:9399. doi:10.3748/wjg.v19.i48.9399

4. Yeo CJ, Cameron JL, Sohn TA, et al. A Six hundred fifty consecutive pancreaticoduodenectomies in the 1990s: pathology, complications, and outcomes. Ann Surg. 1997;226:248-257, 257-260. doi:10.1097/ 00000658-199709000-00004

5. Reid-Lombardo KM, Farnell MB, Crippa S, et al. Pancreatic anastomotic leakage after pancreaticoduodenectomy in 1,507 patients: a report from the pancreatic anastomotic leak study group. $J$ Gastrointest Surg. 2007;11:1451-1459. doi:10.1007/s11605-0070270-4 
6. Lermite E, Pessaux P, Brehant $\mathrm{O}$, et al. Risk factors of pancreatic fistula and delayed gastric emptying after pancreaticoduodenectomy with pancreaticogastrostomy. J Am Coll Surg. 2007;204:588-596. doi:10.1016/j.jamcollsurg.2007.01.018

7. Schmidt CM, Choi J, Powell ES, et al. Pancreatic fistula following pancreaticoduodenectomy: clinical predictors and patient outcomes. HPB Surg. 2009;2009:1-8. doi:10.1155/2009/404520

8. Andrianello S, Pea A, Pulvirenti A, et al. Pancreaticojejunostomy after pancreaticoduodenectomy: suture material and incidence of post-operative pancreatic fistula. Pancreatology. 2016;16:138-141. doi:10.1016/j.pan.2015.11.004

9. Bassi C, Dervenis C, Butturini G, et al. Postoperative pancreatic fistula: an international study group (ISGPF) definition. Surgery. 2005;138:8-13. doi:10.1016/j.surg.2005.05.001

10. Aranha GV, Hodul PJ, Creech S, Jacobs W. Zero mortality after 152 consecutive pancreaticoduodenectomies with pancreaticogastrostomy. $J$ Am Coll Surg. 2003;197:223-231, 231-232. doi:10.1016/S1072-7515(03)00331-4

11. Rezvani M, O’Moore PV, Pezzi CM. Late pancreaticojejunostomy stent migration and hepatic abscess after Whipple procedure. J Surg Educ. 2007;64:220-223. doi:10.1016/j.jsurg.2007.03.002

12. Gaujoux S, Cortes A, Couvelard A, et al. Fatty pancreas and increased body mass index are risk factors of pancreatic fistula after pancreaticoduodenectomy. Surgery. 2010;148:15-23. doi:10.1016/j. surg.2009.12.005

13. Partelli S, Pecorelli N, Muffatti F, et al. Early postoperative prediction of clinically relevant pancreatic fistula after pancreaticoduodenectomy: usefulness of C-reactive protein. Hpb. 2017;19:580-586 doi:10.1016/j.hpb.2017.03.001]

14. Liu QY, Zhang WZ, Xia HT, et al. Analysis of risk factors for postoperative pancreatic fistula following pancreaticoduodenectomy. World J Gastroenterol. 2014;20:17491-17497. doi:10.3748/wjg.v20. i46.17491

15. Ross A, Mohammed S, Vanburen G, et al. An assessment of the necessity of transfusion during pancreatoduodenectomy. Surgery. 2013;154:504-511. doi:10.1016/j.surg.2013.06.012

16. Wang S, Wang X, Li L, Dai H, Han J. Association of preoperative obstructive jaundice with postoperative infectious complications following pancreaticoduodenectomy. Hepatogastroenterology. 2013;60:1274-1279. doi:10.5754/hge121172

17. Faraj W, Alameddine R, Mukherji D, et al. Postoperative outcomes following pancreaticoduodenectomy: how should age affect clinical practice? World J Surg Oncol. 2013;11(131). doi:10.1186/1477-7819$11-131$

18. Fu SJ, Shen SL, Li SQ, et al. Risk factors and outcomes of postoperative pancreatic fistula after pancreatico-duodenectomy: an audit of 532 consecutive cases. Bmc Surg. 2015;15:34. doi:10.1186/ s12893-015-0011-7

19. Lin JW, Cameron JL, Yeo CJ, Riall TS, Lillemoe KD. Risk factors and outcomes in postpancreaticoduodenectomy pancreaticocutaneous fistula. $J$ Gastrointest Surg. 2004;8:951-959. doi:10.1016/j. gassur.2004.09.044

20. Mathur A, Pitt HA, Marine M, et al. Fatty Pancreas: a factor in postoperative pancreatic fistula. Ann Surg. 2007;246:1058-1064. doi:10.1097/SLA.0b013e31814a6906

21. Xia X, Huang C, Cen G, Qiu ZJ. Preoperative diabetes as a protective factor for pancreatic fistula after pancreaticoduodenectomy: a meta-analysis. Hepatobiliary Pancreat Dis Int. 2015;14:132-138. doi:10.1016/s1499-3872(15)60330-7

22. Sandini M, Malleo G, Gianotti L. Scores for prediction of fistula after pancreatoduodenectomy: a systematic review. Dig Surg. 2016;33:392-400. doi:10.1159/000445068

23. Sato N, Yamaguchi K, Chijiiwa K, Tanaka M. Risk analysis of pancreatic fistula after pancreatic head resection. Arch Surg. 1998;133:1094-1098. doi:10.1001/archsurg.133.10.1094
24. Suzuki Y, Fujino Y, Tanioka Y, et al. Selection of pancreaticojejunostomy techniques according to pancreatic texture and duct size. Arch Surg. 2002;137:1044-1047, 1048. doi:10.1001/archsurg.137.9.1044

25. Lee SE, Jang J, Lim C, et al. Measurement of pancreatic fat by magnetic resonance imaging. Ann Surg. 2010;251:932-936. doi:10.1097/SLA.0b013e3181d65483

26. Hu BY, Wan T, Zhang WZ, Dong JH. Risk factors for postoperative pancreatic fistula: analysis of 539 successive cases of pancreaticoduodenectomy. World $J$ Gastroenterol. 2016;22:7797-7805. doi:10.3748/wjg.v22.i34.7797

27. Addeo P, Delpero JR, Paye F, et al. Pancreatic fistula after a pancreaticoduodenectomy for ductal adenocarcinoma and its association with morbidity: a multicentre study of the French Surgical Association. HPB (Oxford). 2014;16:46-55. doi:10.1111/hpb.12063]

28. Chu CK, Mazo AE, Sarmiento JM, et al. Impact of diabetes mellitus on perioperative outcomes after resection for pancreatic adenocarcinoma. J Am Coll Surg. 2010;210:463-473. doi:10.1016/j. jamcollsurg.2009.12.029

29. Hashimoto Y, Sclabas GM, Takahashi N, et al. Dual-phase computed tomography for assessment of pancreatic fibrosis and anastomotic failure risk following pancreatoduodenectomy. J Gastrointest Surg. 2011;15:2193-2204. doi:10.1007/s11605-011-1687-3

30. Ivanics T, Nasser H, Leonard-Murali S, Genaw J. Dehydration risk factors and impact after bariatric surgery: an analysis using a national database. Surg Obes Relat Dis. 2019;15:2066-2074. doi:10.1016/j. soard.2019.09.054

31. Samona S, Hagglund K, Edhayan E. Case cohort study of risk factors for post-thyroidectomy hemorrhage. Am J Surg. 2016;211:537-540. doi:10.1016/j.amjsurg.2015.10.023

32. Weber CE, Bock EA, Hurtuk MG, et al. Clinical and pathologic features influencing survival in patients undergoing pancreaticoduodenectomy for pancreatic adenocarcinoma. $J$ Gastrointest Surg. 2014;18:340-347. doi:10.1007/s11605-013-2388-x

33. Zhou Q, Xia Y, Lei Z. The predictive value of procalcitonin for postoperative early pancreatic fistula. Bmc Surg. 2020;20:90. doi:10.1186/s12893-020-00755-2

34. Hanna MM, Tamariz L, Gadde R, et al. Delayed gastric emptying after pylorus preserving pancreaticoduodenectomy-does gastrointestinal reconstruction technique matter? Am J Surg. 2016;211:810-819. doi:10.1016/j.amjsurg.2015.10.015

35. Sahora K, Morales-Oyarvide V, Thayer SP, et al. The effect of antecolic versus retrocolic reconstruction on delayed gastric emptying after classic non-pylorus-preserving pancreaticoduodenectomy. Am J Surg. 2015;209:1028-1035. doi:10.1016/j.amjsurg.2014.04.015

36. Callery MP, Pratt WB, Kent TS, Chaikof EL, Vollmer CM. A prospectively validated clinical risk score accurately predicts pancreatic fistula after pancreatoduodenectomy. $J$ Am Coll Surg. 2013;216:1-14. doi:10.1016/j.jamcollsurg.2012.09.002

37. Kawai M, Kondo S, Yamaue H, et al. Predictive risk factors for clinically relevant pancreatic fistula analyzed in 1,239 patients with pancreaticoduodenectomy: multicenter data collection as a project study of pancreatic surgery by the Japanese Society of Hepato-Biliary-Pancreatic Surgery. J Hepatobiliary Pancreat Sci. 2011;18:601-608. doi:10.1007/s00534-011-0373-x

38. Li Y, Zhou F, Zhu DM, et al. Novel risk scoring system for prediction of pancreatic fistula after pancreaticoduodenectomy. World $J$ Gastroenterol. 2019;25:2650-2664. doi:10.3748/wjg.v25.i21.2650

39. Ellis RJ, Brock HD, Liu JB, et al. Preoperative risk evaluation for pancreatic fistula after pancreaticoduodenectomy. J Surg Oncol. 2019;119:1128-1134. doi:10.1002/jso.25464

40. Xia W, Zhou Y, Lin Y, et al. Predictive risk scoring system for clinically relevant pancreatic fistula after pancreaticoduodenectomy. Med Sci Monitor. 2018;24:5719-5728. doi:10.12659/MSM.911499

41. You Y, Han IW, Choi DW, et al. Nomogram for predicting postoperative pancreatic fistula. Hpb. 2019;21:1436-1445. doi:10.1016/j. hpb.2019.03.351 
42. Brennan MF, Kattan MW, Klimstra D, Conlon K. Prognostic nomogram for patients undergoing resection for adenocarcinoma of the pancreas. Ann Surg. 2004;240:293-298. doi:10.1097/01.sla.0000133125.85489.07

43. Knight BC, Kausar A, Manu M, Ammori BA, Sherlock DJ, O'Reilly DA. Evaluation of surgical outcome scores according to ISGPS definitions in patients undergoing pancreatic resection. Dig Surg. 2010;27:367-374. doi:10.1159/000313693

44. Pratt W, Joseph S, Callery MP, Vollmer CM. POSSUM accurately predicts morbidity for pancreatic resection. Surgery. 2008;143:8-19. doi:10.1016/j.surg.2007.07.035
45. Pratt W, Callery MP, Vollmer CJ. Optimal surgical performance attenuates physiologic risk in high-acuity operations. $\mathrm{J} \mathrm{Am} \mathrm{Coll}$ Surg. 2008;207:717-730. doi:10.1016/j.jamcollsurg.2008.06.319

46. Zhang JY, Huang J, Yang ZY. Abdominal pain after subtotal gastrectomy: a first report of accessory pancreatic fistula. J Pain Res. 2020;13:431-435. doi:10.2147/JPR.S238599

\section{Publish your work in this journal}

Risk Management and Healthcare Policy is an international, peerreviewed, open access journal focusing on all aspects of public health, policy, and preventative measures to promote good health and improve morbidity and mortality in the population. The journal welcomes submitted papers covering original research, basic science, clinical \& epidemiological studies, reviews and evaluations, guidelines, expert opinion and commentary, case reports and extended reports. The manuscript management system is completely online and includes a very quick and fair peer-review system, which is all easy to use. Visit http://www.dovepress.com/testimonials.php to read real quotes from published authors. 